\title{
A sex attractant of the cabbage webworm, Hellula undalis Fabricius (Lepidoptera: Pyralidae)
}

\author{
Hajime Sugie, ${ }^{1, *}$ Junya YaSe, $^{2}$ Kiyotomo FutaI $^{2}$ and Yoichi Shirai ${ }^{1}$ \\ ${ }^{1}$ National Institute for Agro-Environmental Sciences; Tsukuba, Ibaraki 305-8604, Japan \\ ${ }^{2}$ Hyogo Prefectural Technology Center for Agriculture; Kasai, Hyogo 679-0198, Japan \\ (Received 8 May 2002; Accepted 12 October 2002)
}

\begin{abstract}
Recently, crop damages by the cabbage webworm, Hellula undalis Fabricius (Lepidoptera: Pyralidae), has been frequently observed in Japan, and the development of a species-specific trap for monitoring of the field population is required. Unfortunately, the attraction activity of the known sex pheromone of this species, $(E, E)-11,13$-hexadecadienal, is too weak to be effective in a lure for this trap. Thus, we began field screening tests to find compounds that could enhance the attraction activity of $(E, E)-11,13$-hexadecadienal. In the tests, we found that a mixture of $5 \mu \mathrm{g}$ of $(E, E)$ 11,13-hexadecadienal and 15-500 ng of (Z)-11-hexadecenal showed the same attraction activity as virgin females. The existence of this compound was not confirmed in the extract of virgin females.
\end{abstract}

Key words: Hellula undalis; cabbage webworm; sex attractant; (E,E)-11,13-hexadecadienal; (Z)-11-hexadecenal

\section{INTRODUCTON}

The cabbage webworm, Hellula undalis Fabricius (Lepidoptera: Pyralidae), is distributed in Asia, Africa, and Europe, and is known as a pest of cruciferous vegetables (CAB, 1981). A sex pheromone component of this species has been reported to be $(E, E)-11,13$-hexadecadienal (Arai et al., 1982) and the attraction activity has been confirmed (Koshihara et al., 1985). Later, the attraction activity of this compound was found to be weak, and the addition of geometric isomers of the compound to the component did not increase the attraction activity in the field (Y. Shirai, unpublished). Recently, crop damage by this species has been frequently observed in Japan (Futai et al., 2000; Shibao and Tanaka, 2000), and the development of a species-specific trap is planned for monitoring of the field population. Thus, we began searching for an effective attractant to use as a lure for the trap.

\section{MATERIALS AND METHODS}

Insects. The larvae of $H$. undalis were collected in Kasai City, Hyogo Prefecture in August 1999, and were reared using germinating daikon (Japa- nese white radish) seeds (Yamada and Koshihara, 1981) for successive generations at $23^{\circ} \mathrm{C}$ under $16 \mathrm{~L}-8 \mathrm{D}$. The pupae obtained were placed in plastic eclosion pots at $15^{\circ} \mathrm{C}$ under continuous light. The adults emerged were separated by sex and kept at $23^{\circ} \mathrm{C}$ under continuous light.

Extraction of pheromone. The 2 to 3-day-old female moths were moved to a dark place for $3 \mathrm{~h}$ before extraction. The crude pheromone was extracted from the whole body with $1 \mathrm{ml}$ of hexane in a small glass vial. In a preliminary test, the crude pheromone extracted over night in a refrigerator did not show attraction activity in a field. Thus, it was decided to extract for $10 \mathrm{~min}$. The extracts were stored in a refrigerator until use.

Column chromatography. Column chromatography with Florisil (100/200 mesh, $30 \mathrm{~g}$ ) was carried out according to a class-separating method for lipids (Carroll, 1961). The column was successively eluted with $50 \mathrm{ml}$ of hexane, $120 \mathrm{ml}$ of $5 \%$ ether in hexane, and $150 \mathrm{ml}$ each of $15 \%, 25 \%$, and $50 \%$ ether in hexane.

High pressure liquid chromatography (HPLC). A high pressure liquid chromatograph (HP 1050) with a Rheodyne injector was used. The absorbance at $210 \mathrm{~nm}$ was measured with a UV detector. A Lichrosorb Si-60 column $(2.1 \mathrm{~mm}$

\footnotetext{
* To whom correspondence should be addressed at: E-mail: hsugie@affrc.go.jp
} 
i.d. $\times 250 \mathrm{~mm}$ ) was used to purify the sample derived from virgin females and eluted with 5\% ether in hexane at a flow rate of $1 \mathrm{ml} / \mathrm{min}$. A Nucleosil 100-5SA column ( $4 \mathrm{~mm}$ i.d. $\times 250 \mathrm{~mm}$ ) treated with $\mathrm{AgNO}_{3}$ (van Beck and Subrtova, 1995) was used to purify chemicals and eluted with $20 \%$ ether in hexane at a flow rate of $0.7 \mathrm{ml} / \mathrm{min}$.

Gas chromatography (GC). A gas chromatograph (HP 5880) equipped with a splitless injector and a flame ionization detector, and a capillary column (FFAP, $0.25 \mathrm{~mm}$ i.d. $\times 30 \mathrm{~m}, 0.25 \mu \mathrm{m}$ film thickness) was used under a programmed oven temperature condition: $80^{\circ} \mathrm{C}$ for $0.5 \mathrm{~min}$ up to $220^{\circ} \mathrm{C}$ at $7^{\circ} \mathrm{C} / \mathrm{min}$. The purge delay time was $30 \mathrm{~s}$. $\mathrm{He}$ gas was used as a carrier at a flow rate of $20 \mathrm{~cm} / \mathrm{s}$.

Gas chromatography-mass spectrometry (GCMS). A gas chromatograph-mass spectrometer (JEOL SX102) was used. The temperature of the GC-MS interface was $220^{\circ} \mathrm{C}$. The same kind of capillary column was used under the same conditions as GC. The ionization voltage was $70 \mathrm{eV}$ in the electron impact mode.

Chemicals. $(Z, Z)-11,13-H e x a d e c a d i e n a l$, and (Z)-9-, (E)-9-, (Z)-11-, (E)-11-, (Z)-13-, and (E)13-hexadecenals were synthesized by Shin-Etsu Chem. Co. $(E, E)-11,13$-Hexadecadienal was converted from the $(Z, Z)$-isomer by the method of Sgoutas and Kummerow (1968). All compounds were purified by HPLC using the $\mathrm{AgNO}_{3}$ coated Nucleosil 100-5SA column, and the purity was confirmed by capillary GC to be more than $99 \%$. Each solvent was distilled before use.

Field tests. The field tests were carried out at Tsukuba, Ibaraki Prefecture from 20th to 24th September in 2000 and from 8th to 17th October in 2001. Sticky traps $(23 \times 30 \mathrm{~cm})$ were placed in a grass plot along the road about $0.4 \mathrm{~m}$ above the ground at intervals of more than $7 \mathrm{~m}$. A hexane solution sample was loaded on a cotton rope $(4 \mathrm{~mm}$ o.d. $\times 3 \mathrm{~cm})$ and attached to the trap after 21:00. Field trapping was carried out using one trap for each test sample and three traps baited with three 1-day-old virgin females.

\section{RESULTS AND DISCUSSION}

\section{Attraction activity of fractions from Florisil col- umn chromatography}

The crude extract $(3,600$ female equivalents
(FE)) of virgin female moths was dried on anhydrous sodium sulfate and concentrated with an evaporator at $35^{\circ} \mathrm{C}$. This crude extract was fractionated with the Florisil column and 5 fractions eluted successively by hexane (abbreviated as $\mathrm{H}$, hereafter), $5 \%$ ether in hexane (abbreviated as $\mathrm{E} / \mathrm{H}$, hereafter), $15 \% \mathrm{E} / \mathrm{H}, 25 \% \mathrm{E} / \mathrm{H}$ and $50 \% \mathrm{E} / \mathrm{H}$ were obtained. The attraction activity of the $5 \% \mathrm{E} / \mathrm{H}$ fraction and the mixture of fractions of $\mathrm{H}, 15 \%$ $\mathrm{E} / \mathrm{H}, 25 \% \mathrm{E} / \mathrm{H}$, and $50 \% \mathrm{E} / \mathrm{H}$ were compared at the dose level of $100 \mathrm{FE}$. The activity was observed in the $5 \% \mathrm{E} / \mathrm{H}$ fraction, and no effect of the addition of other fractions was seen (Table 1). Therefore, the attraction activity was considered to be in the $5 \% \mathrm{E} / \mathrm{H}$ fraction.

\section{Analysis of the 5\% E/H fraction}

The $5 \%$ E/H fraction was analyzed by GC-MS. The GC retention times of $(E, E)$ - and $(Z, Z)-11,13$ hexadecadienals were $19.12 \mathrm{~min}$ and $18.75 \mathrm{~min}$, respectively. The GC retention times of the other two geometric isomers were between 17.5-18.5 min. The GC retention time of the tallest peak (19.12 $\min$ ) in the analysis of the $5 \% \mathrm{E} / \mathrm{H}$ fraction fit well with that of authentic $(E, E)-11,13$-hexadecadienal, and the MS spectrum of the tallest peak was also the same as that of $(E, E)-11,13$-hexadecadienal. The amount of $(E, E)-11,13$-hexadecadienal in 1 $\mathrm{FE}$ was calculated to be $0.2 \mathrm{ng}$.

\section{Attraction activity of related compounds}

In order to detect compounds which increase the attraction activity of $(E, E)$-11,13-hexadecadienal, the effect of the addition of some compounds related to $(E, E)$-11,13-hexadecadienal was evaluated.

Table 1. Attraction activity of the eluates from the Florisil column chromatography. Test was carried out from 20th to 24th September, 2000.

\begin{tabular}{|c|c|}
\hline Samples & $\begin{array}{l}\text { No. males caught/trap/day }{ }^{\mathrm{a}} \\
\quad(\text { mean } \pm \mathrm{SE})\end{array}$ \\
\hline $5 \%$ ether/hexane & $12.4 \pm 8.5 \mathrm{a}$ \\
\hline All & $12.4 \pm 9.3 \mathrm{a}$ \\
\hline All except $5 \%$ ether/hexane & $\begin{array}{ll}0 & b\end{array}$ \\
\hline Blank & 0 \\
\hline \multicolumn{2}{|c|}{$\begin{array}{l}\text { a Data }(X) \text { were transformed to the square root of }(X+0.5 \\
\text { and compared by variance analysis. Means followed by th } \\
\text { same letter are not significantly different at the } 5 \% \text { level b } \\
\text { Tukey's test. }\end{array}$} \\
\hline
\end{tabular}


Table 2. Attraction activity of the mixtures of $5 \mu \mathrm{g}$ of $(E, E)-$ 11,13 -hexadecadienal and $50 \mathrm{ng}$ of some compounds

\begin{tabular}{llc}
\hline \multicolumn{1}{c}{ Samples } & $\begin{array}{c}\text { No. males caught/trap/day }{ }^{\mathrm{a}} \\
(\text { mean } \pm \text { SE) }\end{array}$ \\
\hline A from 8th to 10th October, 2001 & \\
EE & $0.7 \pm 0.3 \mathrm{~b}$ \\
EE+Z11 & $7.0 \pm 2.1 \mathrm{a}$ \\
EE+E11 & $1.0 \pm 1.0 \mathrm{~b}$ \\
EE+Z13 & $0 \quad \mathrm{~b}$ \\
EE+E13 & $0.3 \pm 0.3 \mathrm{~b}$ \\
EE+Z11+Z13 & $0.7 \pm 0.7 \mathrm{~b}$ \\
3 females & $1.1 \pm 0.6 \mathrm{~b}$ \\
\hline Brom 11th to 13th October, 2001 & \\
EE+Z9 & 0 \\
EE+E9 $\quad \mathrm{c}$ \\
EE+Z11 & $0.3 \pm 0.3 \mathrm{bc}$ \\
EE+Z11+E11 & $5.0 \pm 0.8 \mathrm{a}$ \\
EE+Z11+Z13 & $5.0 \pm 1.5 \mathrm{a}$ \\
EE+Z11+E13 & $3.3 \pm 1.2 \mathrm{ab}$ \\
Z11 & $5.0 \pm 1.2 \mathrm{a}$ \\
3 females & 0 \\
\end{tabular}

EE: (E,E)-11,13-hexadecadienal, Z9: (Z)-9-hexadecenal, E9: (E)-9-hexadecenal, Z11: $(Z)-11$-hexadecenal, E11: $(E)-$ 11-hexadecenal, Z13: (Z)-13-hexadecenal, E13: (E)-13hexadecenal.

${ }^{\text {a }}$ Data $(X)$ were transformed to the square root of $(X+0.5)$ and compared by variance analysis. Means followed by the same letter in each test are not significantly different at the $5 \%$ level by Tukey's test.

Fifty nanogram of each of the six compounds, $(Z)$ 9-, (E)-9-, (Z)-11-, (E)-11-, (Z)-13- and (E)-13hexadecenals, was added to $5 \mu \mathrm{g}$ of $(E, E)-11,13-$ hexadecadienal. The mixtures containing $(Z)-11$ hexadecenal showed the strongest attraction activity (Table 2). When another compound was added to the mixture of $(Z)$-11-hexadecenal and $(E, E)$ 11,13-hexadecadienal, no effect of the addition was observed (Table 2B). (Z)-11-Hexadecenal (0 to $500 \mathrm{ng})$ was added to $5 \mu \mathrm{g}$ of $(E, E)-11,13$-hexadecadienal to determine the optimum proportion of (Z)-11-hexadecenal. Mixtures of 15 to $500 \mathrm{ng}$ additions showed the same level of attraction activity as virgin females (Table 3).

\section{Examination of the existence of $(Z)$-11-hexade- cenal in the $5 \% \mathrm{E} / \mathrm{H}$ fraction}

In order to examine the existence of $(Z)-11$ hexadecenal in the $5 \% \mathrm{E} / \mathrm{H}$ fraction, the $5 \% \mathrm{E} / \mathrm{H}$ fraction was purified by HPLC using a Lichrosorb Si-60 column. Authentic (E,E)-11,13-hexadecadi-
Table 3. Attraction activity of the mixtures of $5 \mu \mathrm{g}$ of $(E, E)$ 11,13 -hexadecadienal and 0 to $500 \mathrm{ng}$ of $(Z)$-11-hexadecenal. Test was carried out from 14th to 17th October, 2001.

\begin{tabular}{lc}
\hline \multicolumn{1}{c}{ Samples } & $\begin{array}{c}\text { No. males caught/trap/day } \\
\text { (mean } \pm \text { SE) }\end{array}$ \\
\hline EE & $0 \quad \mathrm{c}$ \\
EE+5 ng Z11 & $0.3 \pm 0.3 \mathrm{bc}$ \\
EE+15 ng Z11 & $0.5 \pm 0.3 \mathrm{abc}$ \\
EE+50 ng Z11 & $4.0 \pm 1.2 \mathrm{a}$ \\
EE+150 ng Z11 & $4.5 \pm 1.2 \mathrm{a}$ \\
EE+500 ng Z11 & $2.8 \pm 1.9 \mathrm{ab}$ \\
3 females & $2.9 \pm 1.2 \mathrm{a}$ \\
\hline
\end{tabular}

EE: $(E, E)$-11,13-hexadecadienal, Z11: $(Z)$-11-hexadecenal.

${ }^{\text {a }}$ Data $(X)$ were transformed to the square root of $(X+0.5)$ and compared by variance analysis. Means followed by the same letter are not significantly different at the $5 \%$ level by Tukey's test.

enal was eluted at $8 \mathrm{~min}$, and the three fractions eluted between $0-7,7-10$, and $10-15 \mathrm{~min}$ were collected. Five hundred FE of the fractionated samples were analyzed by GC-MS for the presence of (Z)-11-hexadecenal but this compound was not detected. At these analyses, the limit of detection of this compound was $0.5 \%$ of the amount of $(E, E)$ 11,13-hexadecadienal.

With H. undalis, just one or two larvae can cause severe damage to many cruciferous crops, because the larvae infest the growing points or shoots of young plants (Sivapragasam and Chua, 1997). Therefore, it is important to be able to detect the occurrence of this species at a low larval density level (Shirai and Yano, 1994). The mixture of $(Z)$ 11-hexadecenal and $(E, E)-11,13$-hexadecadienal tested in the present study was shown to be useful as an attractant agent of $H$. undalis in the field.

\section{REFERENCES}

Arai, K., T. Ando, A. Sakurai, H. Yamada, T. Koshihara and N. Takahashi (1982) Identification of the female sex pheromone of the cabbage webworm. Agric. Biol. Chem. 46: 2395-2397.

CAB (Commonwealth Agricultural Bureaux) (1981) Distribution maps of plant pests. No. 427. Wallingford, UK.

Carroll, K. K. (1961) Separation of lipid class by chromatography on Florisil. J. Lipid Res. 2: 135-141.

Futai, K., K. Yamashita and H. Tanaka (2000) Effects of insecticides on the cabbage webworm, Hellula undalis by the leaf-dip method. Proc. Kansai Pl. Prot. 42: 31-32 (in Japanese).

Koshihara, T., H. Yamada, N.Takahashi, T. Andou and K. Arai (1985) Japanese Patent 1262397. 
Sgoutas, D. S. and F. A. Kummerow (1968) Cis-trans isomerization of unsaturated fatty acid methyl esters without double bond migration. Lipids 4: 283-287.

Shibao, M. and H. Tanaka (2000) Effects of insecticides on the cabbage webworm, Hellula undalis (Fabricius) on cabbage. Proc. Kansai Pl. Prot. 42: 35-36 (in Japanese).

Shirai, Y. and E. Yano (1994) Hibernation and flight ability of the cabbage webworm, Hellula undalis in Japan. Jpn. Agric. Res. Quart. 28: 161-167.

Sivapragasam, A. and T. C. Chua (1997) Preference for sites within plant by larvae of the cabbage webworm, Hellula undalis (Fabr.) (Lep. Pyralidae). J. Appl. Entomol. 121: 361-365.

van Beck, T. A. and D. Subrtova (1995) Factors involved in the high pressure liquid chromatography separation of alkenes by means of augmentation chromatography on ion exchangers: Overview of theory and new practical developments. Phytochem. Anal. 6: 1-19.

Yamada, H. and T. Koshihara (1981) Simple mass rearing technique of the cabbage webworm, using germinating daikon seeds. Bull. Veg. \& Ornam. Crops Res. Stn. A8: 125-130 (in Japanese with English summary). 